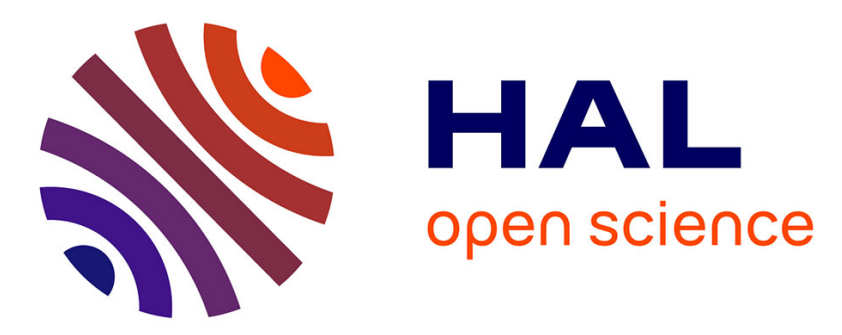

\title{
Robust Optimization for Collaborative Distribution Network Design Problem
}

\author{
Islem Snoussi, Nadia Hamani, Nassim Mrabti, Lyes Kermad
}

\section{To cite this version:}

Islem Snoussi, Nadia Hamani, Nassim Mrabti, Lyes Kermad. Robust Optimization for Collaborative Distribution Network Design Problem. 22nd Working Conference on Virtual Enterprises (PROVE 2021), Nov 2021, Saint-Etienne, France. pp.280-288, 10.1007/978-3-030-85969-5_25 . emse03338939

\section{HAL Id: emse-03338939 \\ https://hal-emse.ccsd.cnrs.fr/emse-03338939}

Submitted on 24 Nov 2021

HAL is a multi-disciplinary open access archive for the deposit and dissemination of scientific research documents, whether they are published or not. The documents may come from teaching and research institutions in France or abroad, or from public or private research centers.
L'archive ouverte pluridisciplinaire HAL, est destinée au dépôt et à la diffusion de documents scientifiques de niveau recherche, publiés ou non, émanant des établissements d'enseignement et de recherche français ou étrangers, des laboratoires publics ou privés. 


\title{
Robust Optimization for Collaborative Distribution Network Design Problem
}

\author{
Islem Snoussi ${ }^{1,2}$, Nadia Hamani ${ }^{1}$, Nassim Mrabti ${ }^{1}$, Lyes Kermad ${ }^{2}$ \\ ${ }^{1}$ Laboratory of Innovative Technology, University of Picardie, 80025 Amiens, France \\ ${ }^{2}$ University of Paris 8, QUARTZ Laboratory, 93200 Saint-Denis, France \\ islem.snoussi@etud.u-picardie.fr, \{nadia.hamani, nassim.mrabti\}@u-picardie.fr \\ 1.kermad@,iut.univ-paris8.fr
}

\begin{abstract}
Collaboration is an interesting solution adopted to improve the levels of sustainability by massifying flows. In this study, we present a new design of a distribution network under uncertainties at two levels in a collaborative context. The proposed network includes suppliers who collaborate to deliver their products to retailers through common platforms. On the other hand, uncertainty is treated in terms of two parameters, namely demands and unit transportation costs. The different used models are validated and analysed by a case study. Computational results provided by the robust model and those given by the deterministic one are compared to evaluate the importance of uncertainty. The effects of uncertainty level on the optimal network configuration are also highlighted.
\end{abstract}

Keywords: Hub Location Problem, Horizontal collaboration, Sustainability, Robust optimisation, Budget of uncertainty

\section{Introduction}

Nowadays, faced with high customer's demands, increasing transport costs and the drawbacks of Covid-19 health crisis on the market, companies find themselves in complex situations. Therefore, they must optimize their logistics operations by opting for a strategy that creates an efficient logistics system. According to [1], [2] and [3], the best solution that should be adopted to solve these problems is the integration of collaboration. In the literature, the latter can be Vertical (VC) or Horizontal (HC) [4]. Besides, [5] asserted that vertical collaboration takes place between partners who belong to the same logistic chain and are not at the same level. This type of collaboration is mainly limited to the sharing of information between partners, while in horizontal collaboration, also named 'pooling', means and resources are shared between partners who are at the same level and do not belong to the same logistic chain [6]. In fact, most of the existing studies focused on VC. However, its performances can be improved only by pooling. HC involves massification of flows through concentrating certain flows on the same site to optimize the supply and distribution circuits. It allows increasing the frequency of delivery, augmenting service rate, 
improving the vehicle fill rate and, thus, reducing the logistics costs and the greenhouse gas (GHG) emissions. An important issue that arises while treating a Distribution Network Design Problem is how to cope with data uncertainty because the parameters of the logistic system are variable. For this reason, the deterministic approach is unfavourable to achieve the mission, such as for long-term strategic decisions like the location of hub facilities related to some parameters (e.g. demands, transportation costs, etc.). In cases where these parameters can be estimated, their probability distributions are determined by using stochastic programming techniques. However, in cases where the only available information is the specification of intervals containing the uncertain values of these parameters, the solution is the robust optimization techniques that can perform well even in the worst-case scenarios [7]. In this paper, we focus on the collaborative distribution network design problem incorporating demand and unit transportation costs uncertainties when the only available information is an interval of uncertainty.

The remainder of the paper is structured as follows. Section 2 is a literature review. Section 3 represents the problem description. Section 4 shows the results produced by each model. Finally, Section 5 is dedicated to the conclusion and our perspectives.

\section{Literature Review}

The distribution network design problem is known as the "Hub Location Problem" (HLP) or "Hub Median Problem" (HMP) [8]. The combination between this problem and the horizontal collaboration is still underdeveloped in the literature [6].

To our knowledge, only Habibi et al. dealt, in [1], with this combination under uncertainties. They studied a robust capacitated hub location problem under the uncertainty of installation costs for two distribution networks. Their objective was to reduce the costs generated by transportation and hub installations treating three cases of collaboration and four cost-sharing strategies. Moreover, Habibzadeh Boukani et al. [9] examined the robust capacitated single allocation and multiple allocation hub location problems under the uncertainty of fixed setup cost and the capacity of each hub using a minimax regret model. The latter is used to minimise the setup and transportation costs. The authors showed that neglecting uncertainty can cause large losses and expenses. Furthermore, Zetina et al. [7] introduced robust counterparts for uncapacitated multiple allocation HLP employing a budget uncertainty model. They presented three different cases of uncertain parameters, namely demands; and transportation costs. The third case was solved using a branch-and-cut algorithm implemented on a commercial solver. Talbi and Todosijević [10] investigated the same problem and proposed a new approach to quantify the robustness of a solution in the presence of uncertainties as it is the case of uncertain demands. So, the approach developed by Sim [11] is, now, considered as a special case. The research work aimed at minimising the transportation costs in the presence of uncertain flows and the model was solved using a heuristic approach which is the VNS (Variable Neighbourhood Search). Correia et al. [12] studied a modelling framework for stochastic Capacitated Multiple Allocation Hub Location Problem with multi-period, dealing with uncertain demands to minimise logistics costs. Martins de Sá et al. [13] proposed a robust 
optimization for multiple allocation hub location problem with uncertain demand flows and fixed setup costs. In their study, the level of conservatism was adjusted by an uncertainty budget. Authors also evaluated the transportation and setup costs and used benders decomposition and a hybrid heuristic approach to solve large scale problems. Rahmati and Bashiri [14] introduced a robust uncapacitated multiple allocation hub location problem with uncertainty of demands, hub establishment fixed cost and inter hub flow discount factor by applying an uncertainty budget model employed to assess the costs generated by transportation and establishing hubs. The same problem was treated by Lozkins et al. [15], but with only uncertain demands by using a set of scenarios and assigning for each one a probability of occurrence. The problem was formulated as a nonlinear stochastic optimisation problem to reduce the hub installation costs, expected transportation costs, and estimated absolute deviation of transportation costs. Besides, two Benders Decomposition strategies were suggested to solve the obtained mathematical model and then, results were compared to each other. Peiro et al. [16] introduced a heuristic procedure for stochastic Uncapacitated r-Allocation pHub Location Problem under demand and cost uncertainties. They also developed a heuristic approach for the deterministic part. The objective of the study was to minimise the total cost by reducing the allocation and the transportation costs. Ben Mohamed et al. [17] suggested a methodology for the stochastic design problem of two-stage distribution networks by integrating demand uncertainty.

In summary, most studies dealing with the uncertain distribution network design problem focused on the economic objective, by reducing logistics costs, and evaluated uncertainties related to the latter and the flows. In this paper, we examine the distribution network design problem with robust optimization to evaluate not only the economic dimension, but also the environmental one under demand and unit transportation costs uncertainties.

\section{Problem Description}

We cite, in the following sub-section, the objectives of the deterministic mathematical model and explain the uncertainty parameters.

\subsection{Objectives of the Deterministic Model}

The mathematical model proposed by Mrabti et al. [6] uses a three-echelon pooled distribution network represented in Figure 1. This distribution network consists of suppliers who collaborate to deliver their products to retailers through shared warehouses and distribution centres. Two objective functions are investigated: the economic function, which minimises logistics costs, and the environmental one that reduces $\mathrm{CO}_{2}$ emissions from vehicles and hubs. The economic objective function, represented by (1), aims to lowering the various logistical costs related to transportation $C T$, storage $C S$, late delivery penalties $C D$, opening hubs $C O$, and handling $C H$. The transportation cost $C T_{i j t}$, represented by (2), depends on the quantity of product $p$ transported between the origin $i$ and the destination $j\left(q_{i j} t^{v}\right)$, the type of vehicle (capacity 
$Q^{v}$, unit costs of empty vehicles $C_{0}{ }^{v}$ and full vehicles $C_{q}{ }^{v}$ ), the travelled distance $d_{i j}$ and the number of the required vehicles or trips $N_{i j t}{ }^{v}$. It is important to consider the delay in delivery when designing a pooled distribution network. Indeed, this delay directly affects the service rate and the retailer loyalty. In some above-mentioned studies, the opening cost was predefined since there is a list of capacity choices. However, in this research work, the cost of installing a hub $m(\mathrm{CWm})$ depends on its area Am and the unit opening cost. It is given by equation (3). The area of the hub $\mathrm{m}$, depending on the capacity of the hub $\mathrm{Cm}$, the unit area of a pallet $A P$ and a coefficient $\alpha$, is obtained by (4).

$$
\begin{gathered}
\mathrm{F}_{1}=\mathrm{CT}+\mathrm{CS}+\mathrm{CD}+\mathrm{CO}+\mathrm{CH} . \\
\mathrm{CT}_{\mathrm{ijt}}^{\mathrm{v}}=\mathrm{d}_{\mathrm{ij}}\left(\frac{\mathrm{Q}^{\mathrm{v}} \cdot \mathrm{C}_{\mathrm{q}}^{\mathrm{v}}-\mathrm{C}_{\mathrm{o}}^{\mathrm{v}}}{\mathrm{Q}^{\mathrm{v}}} \cdot \sum_{\mathrm{p}} \mathrm{q}_{\mathrm{ijt}}^{\mathrm{pv}}+2 \cdot \mathrm{C}_{\mathrm{o}}^{\mathrm{v}} \cdot \mathrm{N}_{\mathrm{ijt}}^{\mathrm{v}}\right) ; \forall \mathrm{t} \in \mathrm{T}_{2}, \mathrm{v} \in \mathrm{V},(\mathrm{i}, \mathrm{j}) \in \mathrm{A} . \\
\mathrm{CW}_{\mathrm{m}}=\mathrm{A}_{\mathrm{m}} \cdot \mathrm{Cw}_{\mathrm{m}} ; \forall \mathrm{m} \in \mathrm{H} . \\
\mathrm{A}_{\mathrm{m}}=\alpha \cdot \text { AP. } \mathrm{C}_{\mathrm{m}} ; \forall \mathrm{m} \in \mathrm{H} .
\end{gathered}
$$

The environmental objective function, represented in (5), is applied to minimise the $\mathrm{CO}_{2}$ emissions due to vehicles $E V$ (caused by their manufacturing, use/depreciation and freight transportation) and to hubs operation (resulting from their constructions $E C$, operations $E O$, heating, cooling, ventilation and auxiliaries, production of domestic hot water, lighting of premises, as well as upkeep and maintenance).

$$
\mathrm{F}_{2}=\mathrm{EV}+\mathrm{EO}+\mathrm{EC} \text {. }
$$

In this study, we consider the collaborative scenario shown in Figure 1. We assume that each supplier is assigned to a single warehouse and that this warehouse can serve multiple distribution centres, while each retailer can only be served by a single distribution centre.

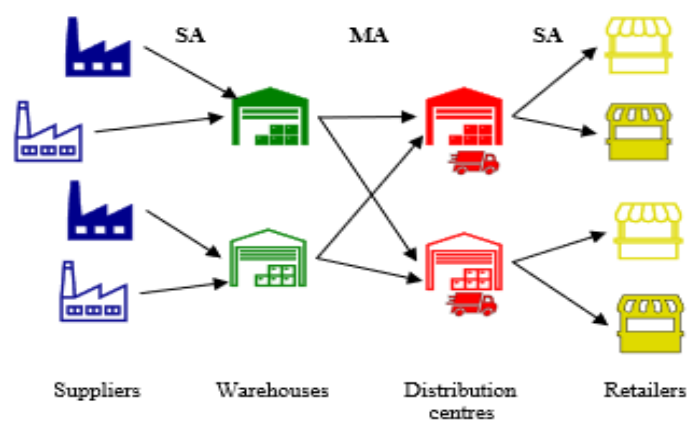

Fig. 1. Example of a collaborative distribution network.

\subsection{Robust Proposed Uncertainties}

Giving that the weaknesses of the stochastic programming make it inadequately used to deal with problems where there is no information about the parameter's distributions, 
we opt for the robust approach already used in several works [9], [10] and [14] to design a collaborative distribution network that can operate in worst-case scenarios. Our model incorporates several uncertainty levels to face the different variations caused by hazards, especially in this period of health crisis caused by COVID-19.

Nowadays, customer's demands cannot be estimated since, during this epidemic, the demands of some companies changed considerably (decrease or increase in sales). Indeed, unit transportation costs vary according to the price of fuel which is very sensitive to several external factors such as geopolitical tensions, epidemics and global growth. Thus, we study the two cases for which the parameters are subject to interval uncertainty. We choose the budget model already applied by [7], [13] and [19] as it offers a certain flexibility to decision-makers to choose more or less efficient solutions through the uncertainty budget that determines the maximum used number of demand (or unit transportation costs). This budget is defined as uncertain parameter. As a result, each uncertain parameter is assumed to have an interval of uncertainty. Demands are defined as $W_{j t}^{p} \in\left[W_{j t}^{p L}, W_{j t}^{p L}+W_{j t}^{p \Delta}\right]$ where $W_{j t}^{p L}$ and $W_{j t}^{p \Delta} \geq 0$ are their nominal and deviation values, respectively. In addition, unit transportation costs are defined as $C_{q}^{v} \in$ $\left[C_{q}^{v L}, C_{q}^{v L}+C_{q}^{v \Delta}\right]$ for the full-loaded vehicles and $C_{0}^{v} \in\left[C_{0}^{v L}, C_{0}^{v L}+C_{0}^{v \Delta}\right]$ for empty vehicles where $C_{q}^{v L}, C_{q}^{v \Delta} \geq 0, C_{0}^{v L}$, and $C_{0}^{v \Delta} \geq 0$ are their nominal and deviation values for each case, respectively. Designing a collaborative distribution network under the mentioned uncertainties causes the nonlinearity of the mathematical models. As a solution, the dual procedure should be used to linearise them and provide a mixed integer linear programming (MILP) optimization problem for each robust counterpart.

\section{Computational Experiments}

In this section, we examine a case study of a French distribution network represented in Figure 2. This network contains 34 nodes that consist of seven suppliers delivering seven products to thirteen retailers via shared warehouses and distribution centres for six weeks. The maximum number of warehouses and distribution centres to be opened is seven for each set. The number of hubs and their storage capacities are determined by the employed model. The resulting MILP formulations are solved exactly using CPLEX and we use $5 \%$ of the uncertain parameters as the initial value of the uncertainty budget. Besides, the latter limits the number of uncertain parameters allowed to deviate from their nominal values. This behaviour is justified by the fact that the case where all parameters deviate from their nominal values are rare.

Table 1 presents a comparative study of the robust optimisation results and the fixed deterministic findings. The fixed deterministic case means that the used parameter values are those found in the worst case [13]. Therefore, the values of these parameters are equal to the nominal ones plus the deviations obtained by solving the robust model. The S.eco and S.env are the economic and environmental objective scenarios, respectively. 


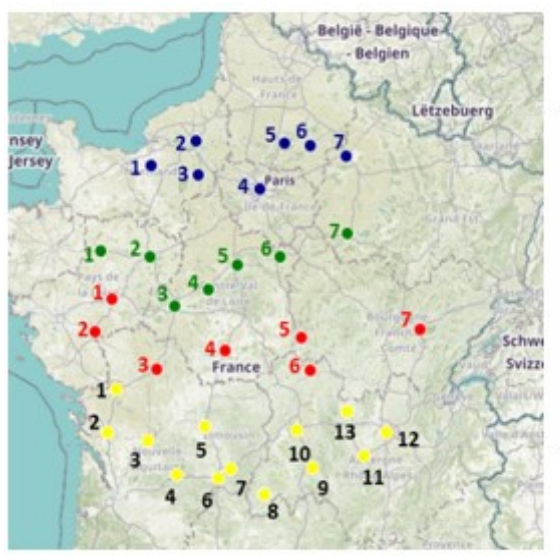

- Suppliers: 1: Lisieux, 2: Rouen, 3: Evreux, 4: Paris,

5: Compiègne, 6 : Soissons, $7:$ Reims

-Warehouses: 1: Laval, 2: Le Mans, 3: Tours, 4: Blois,

5: Orléans, 6: Montargis, 7: Troyes

- Distribution centres: 1 : Angers, 2: Cholet, 3: Poitiers,

4: Châteauroux, 5: Nevers, 6: Moulins, 7: Dole

- Retailers: 1: Niort, 2: Saintes, 3: Angoulême,

4: Périgueux, 5: Limoges, 6: Brive-la-Gaillarde, 7: Tulle,

8: Aurillac, 9: Brioude, 10: Clermont-Ferrand, 11: Saint-

Étienne, 12: Lyon, 13: Roanne

Fig. 1. Set of selected nodes on the map of France.

We note that when $5 \%$ of the uncertain parameters can take their worst-case values, the total logistics cost of the robust approach is lower than that of the deterministic one. Table 2 shows that the total capacities of the hubs in the robust case are lower than those in the fixed deterministic case. We can also conclude that the integration of uncertainty allows saving the space dedicated to storage, which reduces the storage costs and, therefore, minimises the logistic costs, compared to the fixed deterministic case. One of the parameters that highlight the impacts of uncertainty is the number of vehicles in use (See Table 3). Obviously, the robust approach gives better result than the obtained one in the deterministic case, especially for the third type of vehicles that has the highest logistics costs and $\mathrm{CO}_{2}$ emissions. As a result, logistics costs and $\mathrm{CO}_{2}$ emissions are minimised.

Figure 3 demonstrates that, by presenting more opened distribution centres, the optimal configuration obtained in the S.eco scenario for the uncertain demands case is different from the costs case. This behaviour is due to the use of more resources when demands increase.

Table 1. Summary of the results of uncertain demands and unit transportation costs cases.

\begin{tabular}{lllllllll}
\hline Sustainability indicators & \multicolumn{3}{l}{ Demands case } & \multicolumn{4}{l}{ Unit transportation costs case } \\
\hline & \multicolumn{2}{l}{$\begin{array}{l}\text { Fixed } \\
\text { deterministic }\end{array}$} & Robust & \multicolumn{4}{l}{$\begin{array}{l}\text { Fixed } \\
\text { deterministic }\end{array}$} \\
\cline { 2 - 9 } & S.eco & S.env & S.eco & S.env & S.eco & S.env & S.eco & S.env \\
\cline { 2 - 9 } & 2.14 & 2.48 & 1.46 & 1.66 & 1.67 & 1.95 & 1.48 & 1.62 \\
Costs $\left(10^{7} €\right)$ & 4.33 & 4.37 & 3.22 & 3.20 & 3.28 & 3.21 & 3.18 & 3.14 \\
$\mathrm{CO}_{2}$ emissions $\left(10^{9} \mathrm{~g} \mathrm{CO}_{2}\right)$ & & & & & & & &
\end{tabular}


Table 2. Summary Total capacities of hubs.

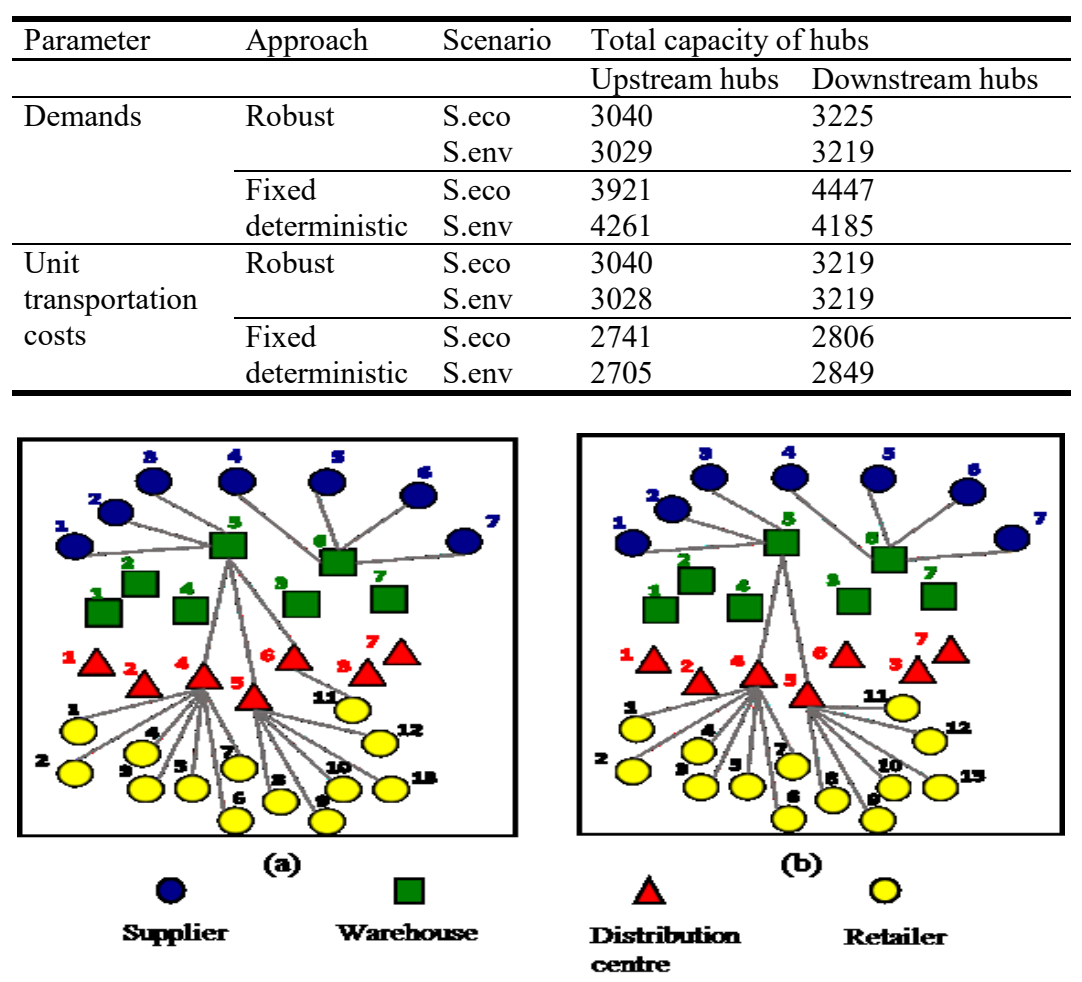

a: Distribution network of demands uncertainty case.

b: Distribution network of unit transportation costs uncertainty case.

Fig. 3. Optimal network configurations of the S.eco scenario.

\section{Conclusion and Perspectives}

This study introduced a collaborative distribution network design problem under uncertainties of demands and unit transportation costs. It minimises logistics costs and $\mathrm{CO}_{2}$ emissions. A case study was examined via a distribution network in France. The obtained results show that the robust optimisation case is better than the fixed deterministic one in terms of costs and $\mathrm{CO}_{2}$ emissions by saving storage space and using a smaller number of vehicles. However, solving the problem exactly with CPLEX limits its size. Thus, it is preferable, in this case, to provide a heuristic method for the resolution of larger instances. We also intend to propose, in our future works, a robust counterpart that considers the uncertainty of the maximum number of vehicles in use and another case that combines demand, unit transportation costs and maximum number of vehicles in use uncertainties. 


\section{References}

1. Habibi, M.K.K., Allaoui, H., Goncalves, G. Collaborative Hub Location Problem under Cost Uncertainty. Comput. Ind. Eng. 2018, 124, 393-410, doi:10.1016/j.cie.2018.07.028.

2. Ferrell, W., Ellis, K., Kaminsky, P., Rainwater, C. Horizontal Collaboration: Opportunities for Improved Logistics Planning. Int. J. Prod. Res. 2020, 58, 4267-4284, doi:10.1080/00207543.2019.1651457.

3. Aloui, A., Hamani, N., Derrouiche, R., Delahoche, L. Systematic Literature Review on Collaborative Sustainable Transportation: Overview, Analysis and Perspectives. Transp. Res. Interdiscip. Perspect. 2021, 9, 100291, doi:10.1016/j.trip.2020.100291.

4. Ouhader, H., Kyal, M.E. Assessing the Economic and Environmental Benefits of Horizontal Cooperation in Delivery: Performance and Scenario Analysis. Uncertain Supply Chain Manag. 2020, 303-320, doi:10.5267/j.uscm.2019.12.001.

5. Moutaoukil, A., Derrouiche, R., Neubert, G. Pooling Supply Chain: Literature Review of Collaborative Strategies. In Collaborative Networks in the Internet of Services, CamarinhaMatos, L.M., Xu, L., Afsarmanesh, H., Eds., IFIP Advances in Information and Communication Technology, Springer Berlin Heidelberg: Berlin, Heidelberg, 2012, Vol. 380 , pp. 513-525 ISBN 978-3-642-32774-2.

6. Mrabti, N., Hamani, N., Delahoche, L. The Pooling of Sustainable Freight Transport. J. Oper. Res. Soc. 2020, 0, 1-16, doi:10.1080/01605682.2020.1772022.

7. Zetina, C.A., Contreras, I., Cordeau, J.-F., Nikbakhsh, E. Robust Uncapacitated Hub Location. Transp. Res. Part B Methodol. 2017, 106, 393-410, doi:10.1016/j.trb.2017.06.008.

8. Hu, L., Zhu, J.X., Wang, Y., Lee, L.H. Joint Design of Fleet Size, Hub Locations, and Hub Capacities for Third-Party Logistics Networks with Road Congestion Constraints. Transp. Res. Part E Logist. Transp. Rev. 2018, 118, 568-588, doi:10.1016/j.tre.2018.09.002.

9. Habibzadeh Boukani, F., Farhang Moghaddam, B., Pishvaee, M.S. Robust Optimization Approach to Capacitated Single and Multiple Allocation Hub Location Problems. Comput. Appl. Math. 2016, 35, 45-60, doi:10.1007/s40314-014-0179-y.

10. Talbi, E.-G., Todosijević, R. The Robust Uncapacitated Multiple Allocation p-Hub Median Problem. Comput. Ind. Eng. 2017, 110,322-332, doi:10.1016/j.cie.2017.06.017.

11. Bertsimas, D., Sim, M. Robust Discrete Optimization and Network Flows. Math. Program. 2003, 98, 49-71, doi:10.1007/s10107-003-0396-4.

12. Correia, I., Nickel, S., Saldanha-da-Gama, F. A Stochastic Multi-Period Capacitated Multiple Allocation Hub Location Problem: Formulation and Inequalities. Omega 2018, 74, 122-134, doi:10.1016/j.omega.2017.01.011.

13. Martins de Sá, E., Morabito, R., de Camargo, R.S. Benders Decomposition Applied to a Robust Multiple Allocation Incomplete Hub Location Problem. Comput. Oper. Res. 2018, 89, 31-50, doi:10.1016/j.cor.2017.08.001.

14. Rahmati, R., Bashiri, M. Robust Hub Location Problem with Uncertain Inter Hub Flow Discount Factor. 2018, 10

15. Lozkins, A., Krasilnikov, M., Bure, V. Robust Uncapacitated Multiple Allocation Hub Location Problem under Demand Uncertainty: Minimization of Cost Deviations. J. Ind. Eng. Int. 2019, 15, 199-207, doi:10.1007/s40092-019-00329-9.

16. Peiró, J., Corberán, Á., Martí, R., Saldanha-da-Gama, F. Heuristic Solutions for a Class of Stochastic Uncapacitated P-Hub Median Problems. Transp. Sci. 2019, 53, 1126-1149.

17. Ben Mohamed, I., Klibi, W., Vanderbeck, F. Designing a Two-Echelon Distribution Network under Demand Uncertainty. Eur. J. Oper. Res. 2020, 280, 102-123, doi:10.1016/j.ejor.2019.06.047.

18. Hamaz, I. Méthodes d'optimisation robuste pour les problèmes d'ordonnancement cyclique, Université Paul Sabatier: Toulouse III, France, 2018. 